\title{
Changes, Challenges and Innovation in the Local Government Public Services of the New Media Era
}

\author{
Jiang $\mathrm{Ke}$ \\ School of Public Management \\ Yunnan University of Finance and Economics \\ Kunming, P.R. China \\ (1341824069@qq.com)
}

\begin{abstract}
With the rapid development of the Internet and mobile communications equipment as the core of the new media, the new media is different from traditional media ,such as newspapers, radio, television and so on, which because of the new media crosses times and space, spreads fast, interactive efficiently, and its high autonomy, and it profoundly changes the traditional way of supplying public services, breaking the old local government public service system. It is necessary to use new media innovative means of local government public services effectively, improve public service capacity and level of government control.
\end{abstract}

Keywords—new media; local government; public services; innovation

\section{INTRODUCTION}

The new media is relative to the traditional media, new media forms developed after newspapers, radio, television and other traditional media. Digital technology, network technology, mobile technology, the Internet, wireless communications networks, satellite channels, etc. as well as computers, mobile phones are used to provide users with information and entertainment services in the shape of media forms of communication pattern. Therefore, how to effectively use new media to innovate local government public services, promote the ability of local government's controlling level will become a very important issue.

\section{A Fundamental Change in the New Media ERA LOCAL GOVERNMENT PUBLIC SERVICES}

New media is a new concept relative to traditional media, which is built on the digital technology, Internet technology, mobile communications technology media forms. Its diverse manifestations, main categories including news sites, online community forums, blog, social networking sites, instant messaging networks, new media video, mobile news, mobile TV, China IPTV digital television, digital newspapers, and electronic paper. The new media is gradually changing the government in the center, top-down traditional public service model.

\section{A. New media promotes the concept of local government public service transformation}

Emergence of new media, to some extent, can promote the transformation of local government public service concept, including the transparent transition from mystery, regular from random. From government-centered to citizen-centered change like a practical sense, that is, the concept of public service innovation. With the popularity of the new media. Many local governments and administrative staff have begun to realize the importance of public service information technology. The public services are trying to change traditional media, which is dominated by the traditional media and new media combination. At the same time, this also makes executives come to realize that the traditional concept of the administrative, management and service means has been unable to adapt to the requirements of the new media age. Government officers should gradually shift from "official position" of the administrative concept to "people-based" principle of service up, get rid of those who are already outdated management philosophy, and establish the concept of service-oriented government. [1] To the grass-roots government public needs as the starting point, to serve the purpose, make full use of new media and optimization services, and constantly strengthen the public service information technology. Improving public service grassroots government, satisfy service needs of citizens.

\section{B. New media change the l forms of local government and public service}

The most obvious change in the new media for local government public service is that it improves the means and forms of local government public services. From face- to- face services to the internet and other technology-based point to point services, and technology innovation. At the new media age, the local government public infrastructure and services continue to be strengthened. Culture, education, social security, health care, administrative licensing, patent applications, registration, payment of taxes and other public services are using Internet technology, mobile communication technology, digital technology and other advanced information technology. Gradually, they change the public service ways for citizens, which provide more convenient and efficient services. And then to the greatest extent to meet the needs of citizens and business. 
At present, many local governments have set up their own service website. Most local government sites have basically achieved the release of public information to the public service function, including education, culture, employment, medical and business management, quality inspection, and so on. Some important local government departments such as taxation, industry and commerce, customs, hospitals have been offering a variety of online services. Some government websites have online application service between Hongkong and foreign personal travel endorsement, Hongkong and Macao and overseas to visit relatives and other projects. Local tax system in terms of online office at the forefront of other sectors. Basically achieved all project work guidelines, download forms, online reporting, query work progress, view the results of handling, and a series of online consulting business. Information construction of local government public service has entered the development stage, and promote local governance systems and governance modernization.

\section{New media achieve a real sense of community citizen participation}

Compared to traditional media, new media crosses time and space, interactivity, autonomy, information and other features as well as its mass rapid dissemination of information, coupled with advanced Internet technology, the popularity and application of digital technology for the community to provide citizen participation unprecedented convenience. Whether the political sphere and scale and the frequency of the social sphere citizen participation is much higher than traditional times. First, the new social media improves the active participation of citizens. Independent new media, interactive, real-time as well as its openness has played down the totalitarian features. For the immediate understanding of the relevant public citizen service information to provide a more convenient conditions than in the past, but also for decision-makers to understand their needs and provides more ways to form a second, new media for the community to provide fast channel citizen participation. From traditional media to new media can be said to be a citizen participation process to gradually reduce the threshold.

\section{Challenges That local Government Public Services Face at the New Media ERA}

\section{A. Difficult transition of ideology}

Because of influence of traditional feudal system, it's difficult for our system of government to get rid of administrative controls, bureaucracy, formalism, hedonism, paternalism, privileges phenomenon, although since the reform and opening up has made great progress, but big government, small society form is still very serious, our government called omnipotent government, taking the all-powerful functions to all public services, but the specific time that the service provider is a public service provided by the Government does not give, but often occur buck-passing, arbitrary collection of taxes, etc. phenomenon, most of that in relation to wholeheartedly engage in service-oriented government investment, engage in advanced technology, economic construction, while the back of the head people of concern to the vital interests of throwing little attention. Essentially public services must focus on the public interest, public service, will give the market the rights and services, the target set for the public service.

\section{B. Imperfect ways of public services}

In this stage, in addition to traditional public services, local government services delivery through the new media means to the main government website. Provide education, health care, apply for licenses, and pay taxes and other financial services for citizens and businesses through government websites. This way is single service, so that the lack of information technology application ability of citizens and other vulnerable groups is difficult to obtain public services. You should also take a variety of public services, such as smart phones, tablet PC, digital television, call center and other services means. Since the economic disparities between different regions, cultural and educational imbalance, so that district, there has been some differences between urban and rural sectors. Thus, in the new media age, there will be the basis for the development of public services caused by the unsound. In addition, the imbalance of information technology and personnel infrastructure uneven distribution will bring the development of public services is not perfect.

\section{Public services are not complete enough}

New media era, completeness of government public services is inadequate. First, effectiveness of public services needs to be improved. At present, the Chinese government use the Internet, public services and other digital mobile communications terminal equipment are provided by the quality, breadth and timeliness of information dissemination have deficiencies. Secondly, the lack of personalized service. Most local governments provide the personalized service that has many deficiencies. Some government websites, especially websites and even grass-roots government does not provide a personal service.

\section{The lag of public services development}

Currently, the Public Services of the basic work is still lagging behind. New media means can't provide enough public services network environment construction to meet the needs of all public services. In the traditional public service basis, local governments provide services is the main way that government services website. Unity grassroots public service routes to make the coverage of public services becomes limited. Local governments provide public services through the new media means to be obtained by the citizens of more urban and economically developed areas, while what to be obtained by the central and western regions citizens. Meanwhile, China's overall information system level is slowly, there is a large gap compared with developed countries. Due to the different regions, the level of citizens' access to economic opportunities of information resources are different, so the citizen of resources scarce is difficult to obtain public services provided by the government through the new media means. 


\section{The Government Public Service InNOVATION OF NeW MEDIA AgE LOCAL}

\section{A. To establish a modern service concept and raise awareness}

Emergence of new media promotes the traditional concept of public service and gradually shift to a modern service concept in certain extent. It is difficult to achieve rational knowledge of public service information technology leave the New Ideas in Public Service to talk about information technology. Should completely change the conceptual level, establish a citizen-centered service concept. Strengthen public service information rational knowledge, it is to the most important part to achieve public service information technology.[2]

\section{1) Establish a citizen-centered service philosophy.}

The construction of Local public service information is not only to meet the development requirements of the new media age, the most fundamental thing is to satisfy the needs of society citizens and businesses. Therefore, the evaluation index system of local government performance included public service information construction, as the actual effect measure of performance evaluate the public service.

\section{2) Strengthen the rational knowledge of information} construction.

At present, some grassroots public services electronically are very macro program, but the actual effect is not satisfactory, often a huge investment of resources and with no match. It needs to select a tangible effect of public services, so deep, so thoroughly and do every aspect related to convene an expert group and sum up, improve, improve. Then according to the steps in the construction process and experience. Select the next service project, continue to advance, which is can be avoid certain risks.

\section{B. Enhance service Website and Integration of resources}

Local government information resources and services portal content development is a priority of local e-government construction, but also an important way to promote local governance system and governance capacity modernization. New media age, the development of local government public services should follow the laws of the grass-roots egovernment construction, integration of resources, unified planning, improve the public service system and enhance the vitality of the public service.

\section{1) Integrate government information resources.}

Strengthen information resource portal website construction and public service activities in the past, the new media era formed. Through the development of information resources, Government use and sharing of information resources including both internal and external information resources to achieve the organic integration with the public service resources. Among them, the government portal has become the online government information and services the main channel from the experience of countries, the government portal website construction must be demand-driven basis. Grasp interactive features, optimize website design, to achieve their true online services.

\section{2) Strengthen government services portal website construction.}

Local government services portal construction must: (1) demand-oriented is the foundation. orienting demand of citizens and businesses, which is the principle of new media era government must be adhered to the public from the need to integrate all regions and sectors of information resources and services, as much as possible the needs of citizens and businesses are at the grassroots level government service web presence and can get the service information resources for all government departments and agencies through a site. [3] (2) Interactivity is the key. The biggest feature of the new media is interactive, not only among government departments, agencies, but also in between the local government and citizens, businesses. Therefore, the scientific website design services, website optimization is an important part can't be ignored.

\section{To achieve collaborative service sector and Reengineering processes Information Technology information}

The construction of government technology gradually from a single government department to focus expanded. There is no unified planning and standards, but only the realization of electronic and information technology in the traditional public service both processes. Therefore, the government is likely to cause a business process system based on the idea, continue to promote the government process reengineering, try to break the barriers between departments, make up the loopholes of service departments to achieve seamless collaboration service.

\section{1) Basic connotation of the Government.}

Government Process Reengineering (GPR) refers, in certain political environment, government processes for review and rethink. By the original process to clean up, simplify and integrate government processes in order to achieve scientific and efficient, that is by design optimization process, enabling the government to better provide customers with convenient, integration of public services. [4] Its main contents are: the public service as the core. A "one-stop" public government as the goal, "service chain" as a link to establish a service-oriented government. [5]

2) The basic idea of the government process reengineering.

In the traditional administrative system, local government departments there is a strict relationship between different levels of membership on. Departments formed only "responsible for the" administration concept. Interactivity of New media. Therefore, we must break the traditional administrative system under the department on the lower level between affiliation, into a relationship of mutual cooperation between departments, between the various positions on the center in order to link up with each other, to achieve seamless collaboration services, to form a complete "service chain", and ultimately effective grassroots public services to meet the overall growth of the grass-roots demand for public services, upgrades and increasingly diverse needs. 


\section{The implementation of modern human resources strategy and established CIO system}

Implementation of information technology personnel training strategy. New media applications, in essence, is the message of the traditional process of public service work, for which the requirements of grass-roots government executives must master certain basic knowledge and application of information technology. Grassroots government should be based on requirements of the new media era, targeted to the grassroots civil servants message basics education and training, the popularity of computer and network knowledge to improve the operational capacity of grass-roots government civil servants. First, the government should attach great importance to the grassroots knowledge training administrative staff, knowledge and some of the old content to be updated. Government officials at the grassroots level have a sense of innovation and ideas; secondly. Computerized training of administrative staff to strengthen the grass-roots level, and the theoretical knowledge into practice to improve its information technology capabilities to enable it to achieve paperless office and online interactive operation in the daily work of government. [6]

\section{E. Narrowing the "digital divide" and expanding the service}

Local governments In order to achieve public service functions in the true sense, just only a way to expand the variety of services. Simultaneously. The "digital divide" ubiquitous and increasingly prominent, local governments must strengthen the construction of infrastructure, the implementation of information technology education, optimizing information systems. The maximum extent possible to narrow the "digital divide" to achieve equalization of public services. Therefore, only way to expand the variety of basic services, grass-roots government's public service functions in order to achieve a real sense, the construction people are satisfied with the service-oriented government. [7] In fact, in addition to basic government services website, as well as digital TV, mobile phones, kiosks, call centers and any other information exchange tools and means having a receiving and delivery functions can be used as a digital terminal becomes a grassroots public service supply route.

\section{F. Strengthen supervisor and improve the quality of public services}

In order to ensure the smooth progress of the new media era grass-roots government's public service building them before, during, and afterwards a full range of oversight is particularly important.

\section{1) Internal oversight.}

Internal local government departments have the appropriate quantitative management mechanisms and tools, such as regular assessment and incentive mechanism, promotion and dismissal mechanisms, and so on. (1) Establish a preventive monitoring mechanism. Preventive monitoring mechanisms, investigation into the post beforehand prevention, curbing abuses from the source. (2) The establishment of performance evaluation mechanism. Establish a public service-oriented grassroots Performance Evaluation System. Therefore, the establishment of scientific performance evaluation mechanism will be incorporated into the construction of grass-roots public service performance appraisal of the scope of party and government organs, assessment of scientific, standardized, full use of resources is an important means to effectively improve the quality of public services.

\section{2) External oversight.}

The so-called external oversight, supervision and management of other powers mainly as an administrative system outside the system, including the organs of state power supervision, judicial supervision, supervision of political parties, social supervision. (1) Strengthen the administrative supervision and restraint mechanisms. Including: strengthening the supervisory role of the grass-roots organs of state power, improve discipline inspection and supervision organs of public service building in the region and its ability to lower levels of oversight. (2)To establish a broad, flexible social oversight mechanisms. Due to the involvement of new media, the scale and frequency of grass-roots citizen participation in public services are much higher than in the past, the need to establish a broad, flexible social oversight mechanisms., includingthe need to strengthen public supervision. In particular, strengthen supervision and awareness of citizens. At the same time, public opinion can be established by evaluation mechanisms.

\section{CONCLUSION}

New media between the government and the public has set up a smooth, convenient and efficient service bridge for local governments continued innovation in public services and governance to achieve modernization to provide a broad space. Therefore, the new media is an understanding of the social aspirations of citizens, public communication, convey important information channels. Both among policy makers and the public, or between the public and the public, with the advent of the new media age, there are more interactive and equality, so closer to the public and grass-roots government to a certain extent the new media distance.

\section{REFERENCES}

[1] (US) ES - Savas: "Privatization and public-private sector partnership," Chinese People's University Press .2002

[2] Lu Tao of Government Public Service Innovation Study. [J]. Ezhou University .2014.10

[3] Lou Cequn, Liu Guangrong overseas experience of e-government development and enlightenment $\mathrm{c}$.

[4] Linden R M. seamless government: the public sector recycling guide [M] Wang Dahai Beijing: China Renmin University Press, 2002.

[5] Wang Shuwen,Li Qing Government Reform and Governmentprocess reengineering THEORY, 2004, (12).

[6] Fan Ling. Our e-government personnel education and training of institutionalization of Daily .2007-08-20 sun and the moon light.

[7] Lee was flat. Deletion and redress the Government Public Service Function [J]. Jiangxi Administration School of Technology, 2005 (3): 6. 